\title{
Response to different medical treatment options for mastalgia in fibrocystic breast disease Mostary $\mathrm{S}^{\mathrm{a}}$, Khan $\mathbf{M M H}^{\mathrm{b}}$, Hossain MAMc, Maitra TK ${ }^{\mathrm{d}}$
}

\begin{abstract}
Background: Fibrocystic breast disease is the most common type of benign breast disease and mastalgia is the most common symptom of fibrocystic breast disease. Various types of medical management are given as a gold standard treatment for that. The aim of this study was to compare the effects of different commonly used medical management options of mastalgia of fibrocystic breast disease on the quality of life of patients and their side effects as well.

Methods: This quasi-experimental study was carried out in Out-patients Department of General Surgery, BIRDEM General Hospital, Dhaka, from July 2018 to June 2019. Total 45 patients with fibrocystic breast disease were selected according to the eligibility criteria and were allocated to two groups by alternative random selection. In non-pharmacological treatments receiving group, lifestyle modification advices along with evening primrose oil were given. On the other hand, in pharmacological treatment receiving group, bromocriptine and danazole were given according to some selection criteria of the patients. Response of treatments to each group and side effects were determined at one month, three months and six months follow-up respectively. Mastalgia was measured by visual analogue scale (VAS) score and quality of life was calculated by modified WHO-QOL scoring in each follow-up.

Results: Patients had an average age of 30.24 6.93 years with a majority in the age group 31-35 years (33.3\%). Most patients were married (64.4\%), housewives (62.20\%), from middle-class groups (62.20\%), multiparous (57.78\%) and the majority had absence of the family history of breast diseases (84.45\%). Majority of them presented with cyclical mastalgia (57.78\%), bilateral mastalgia (60\%) and mastalgia with lumpiness (44.4\%). Among the patients who received non-pharmacological treatment, mastalgia improved in $34.78 \%$ cases and patients received pharmacological treatment, mastalgia improved in $72.73 \%$ cases. Different domains of quality of life were improved significantly in patients who received pharmacological treatment. Though majority of the patients had side effects due to pharmacological treatment, they were well tolerated.
\end{abstract}

Conclusion: Despite having various side effects, pharmacological management by danazol or bromocriptine was well tolerated to our patients and a dramatic improvement was observed on quality of life than the nonpharmacologically treated patients.

Keywords: fibrocystic breast disease, mastalgia, evening prime rose oil, EPO, danazol, bromocriptin, quality of life.

(BIRDEM Med J 2022; 12(1: 22-29)

\section{Author information}

a. Samia Mostary, Assistant Professor, Department of Surgery, Aichi Medical College and Hospital, Amulia, Demra, Dhaka, Bangladesh.

b. Md. Manir Hossain Khan, Associate Professor, Department of Surgery, Bangabandhu Sheikh Mujib Medical University, Shahbag, Dhaka, Bangladesh.

c. Md. A. Mottalab Hossain, Professor, Department of Surgery, Sir Salimullah Medical College and Mitford Hospital, Dhaka, Bangladesh.

d. Tapash Kumar Maitra, Professor \& Head, Department of General Surgery, BIRDEM General Hospital \& Ibrahim Medical College, Shahbag, Dhaka, Bangladesh.

Address of correspondence: Samia Mostary, Assistant Professor, Department of General Surgery, Aichi Medical College and Hospital, Amulia, Demra, Dhaka, Bangladesh. Email: dr.samiamostary@gmail.com

Received: May 24, 2021

Revision received: October 22, 2021

Accepted: October 31, 2021 


\section{INTRODUCTION}

Benign breast disease (BBD) is an umbrella term for various non-malignant breast lesions, such as cysts, tumors, trauma, mastalgia, and nipple discharge. ${ }^{1}$ Fibrocystic breast disease (FBD) is the most common type of benign breast disease and mastalgia is the most common symptom of FBD. ${ }^{2}$ Fibrocystic breast disease represents a spectrum of clinical, radiological and histological findings of the breast in both asymptomatic and symptomatic women. It is a condition of breast where there may be breast pain, breast lumpiness, nodularity and sometimes breast lump; which can sometimes cause discomfort, often periodically related to hormonal influences from the menstrual cycle. Mastalgia causes concern and fear of breast cancer and has negative effects on quality of life. ${ }^{3}$ Mastalgia caused by fibrocystic breast disease is treated by breast specialists as well as by those not specialized in breast diseases. ${ }^{4}$ Unfortunately, these patients are treated inappropriately for prolonged duration with nonpharmacological management by Evening Primrose $\mathrm{Oil}^{2,5}$ in a fear of more side effects of pharmacological managements by certain drugs. ${ }^{6}$ Inappropriate selection of non-pharmacological treatment as a first line management option, sometimes creates financial burden and unchanged or recurrence of clinical symptoms. ${ }^{7}$ Recent population based and breast clinic-based studies suggest that up to $70 \%$ of women experience breast pain in their lifetime. ${ }^{8}$ Moreover, $10 \%$ of symptomatic participants had suffered breast pain for over half their lives. Of the symptomatic participants, $41 \%$ and $35 \%$ reported breast pain affecting the quality of life. ${ }^{9}$ Fifteen percent of women who present to a breast clinic with mastalgia will require treatment. 8,9

Non pharmacological options of medical managements includes some life style modifications (LSM) like- an appropriately fitting and supportive bra, avoidance of caffeine drinks, reduction of dietary fat, increase fiber rich diet, physical exercise to reduce weight and relaxation training are said to be helpful for the treatment of mastalgia ${ }^{10}$ and some nutritional supplementations like oil of evening primrose (EPO) will help more than half of these women ${ }^{5,10,11}$. For those with intractable symptoms, Pharmacological options of medical management like- an anti-gonadotropin, $\left(\right.$ Danazol $\left.^{6}\right)$, or a prolactin inhibitor (Bromocriptine ${ }^{5}$, may be tried. Very rarely, it is necessary to prescribe an anti-estrogen, for example tamoxifen ${ }^{12,13}$, or a luteinizing hormonereleasing hormone (LHRH) agonist to deprive the breast epithelium of estrogenic drive. Surgical interventions have a limited role in the manage-ment of mastalgia ${ }^{5}$ but last-resort options for unresponsive and severe debilitating breast-pain include mastectomy with reconstruction. ${ }^{14}$

The aim of our study was to assess the responses of various medical treatment options of mastalgia of FBD on women's quality of life as well as side effects of used medications.

\section{METHODS}

It was a quasi-experimental study carried out in Outpatient department (OPD) of General Surgery, BIRDEM General Hospital, Dhaka, from July 2018 to June 2019. Forty five patients with fibrocystic breast disease (FBD) presented in OPD of BIRDEM General Hospital, Dhaka, Bangladesh; based on some selection criteria. The inclusion criteria were: women of reproductive age group and patients diagnosed as fibrocystic breast disease by clinical, radiological or cytological examinations within the study period. Patients with suspected breast lesion or diagnosed breast malignancy, pregnant, lactating women and who are planning to have pregnancy in near future, history of any breast surgery or having congenital disability of breast were excluded from this study.

A thorough history of each patient was obtained and careful physical examination carried out of each patient. Hormonal assay and USG of both breasts were done in every patient but Mammography and FNAC were done only in suspected cases to exclude FBD and occult breast carcinomas, particularly in patient having family history of breast diseases.

Patients were allocated to two groups by alternative random selection (first one to non-pharmacological and second one to pharmacological, third to again nonpharmacological treatment receiving group and so on). Non-pharmacological treatments receiving group were given life style modification (LSM) advices along with Evening Primrose Oil (EPO). The LSM advices were wearing a supportive bra, exercise to reduce weight, reduction of mental stress by relaxation therapy, some dietary advises such as reduction of fat and caffeine intake, increase dietary fiber intake, etc. Evening Primrose Oil (EPO) was given orally in a dose of $1000 \mathrm{mg}$ 
thrice daily. In pharmacological treatment receiving group Bromocriptine and Danazole were given according to some selection criteria of the patients. Bromocriptine was given orally in a dose of $2.5 \mathrm{mg}$ twice daily, in those patient with increased prolactin level, having no known hypersensitivity to it, not taking any anticonvulsant, not having uncontrolled diabetes, severe ischemic heart disease or migraine. On the other hand, Danazole was given orally in a dose of $100 \mathrm{mg}$ twice daily in patients with normal prolactin level, hyperestrogenaemia, patients with no undiagnosed genital bleeding, previous thromboembolic disorders or markedly impaired hepatic, renal or cardiac functions. In both groups oral analgesics were given according to the severity of mastalgia. Acetaminophen was given $500 \mathrm{mg}$ thrice daily for VAS 2-4 and Ibuprofen was given $200 \mathrm{mg}$ twice daily for VAS e" 6 in initial visit for one week to alleviate the severity of pain in both groups. Patients were advised not to take any analgesic after initial one week and report if the pain became intolerable.

Response to each group of treatments, side effects \& compliance of the patient were determined at 1 month, 3 months and 6 months follow up respectively. Mastalgia was measured by VAS score and QOL were calculated by modified WHO-QOL scoring (field trial version) in each follow up.

Any side effects, willingness to continue the treatment were also asked to every patient in each follow up. No treatment was changed before 3 months of therapy, no matter what the response was. This study focused simply on the comparison of the two groups of medical treatments of mastalgia and their responses of QOL at beginning and after 6 months of treatment.

\section{RESULTS}

Total number of respondents were 45. Highest respondents of our study were aged between 31 to 35 years $(33.3 \%)$ and no respondents were aged between 45 to 50 years $(0 \%)$. Mean age of the respondents were $30.24 \pm 6.93$ years of SD. Among the attended, maximum patients were married $(64.4 \%)$, house wife(62.20\%), middle class $(62.20 \%)$, multipara $(57.78 \%)$, had regular menstruation (77.8\%) and absence of family history of breast disease among them was more (84.45\%) (Table I).

Table I Demographic characters of the respondents $(\mathrm{N}=45)$

\begin{tabular}{llcc}
\hline Demographic characteristics & Types & Frequency & Percentage \\
\hline Age (years) & 16 to 20 years & 4 & 8.9 \\
& 21 to 25 years & 10 & 22.2 \\
& 26 to 30 years & 11 & 24.4 \\
& 31 to 35 years & 15 & 33.3 \\
& 36 to 40 years & 3 & 6.7 \\
& 41 to 45 years & 2 & 4.4 \\
Marital Status & 46 to50 years & 0 & 0 \\
Occupational status & Single & 13 & 35.6 \\
& Married & 32 & 64.4 \\
Socio-economic status & House wife & 24 & 62.20 \\
& Student & 14 & 24.40 \\
Menstrual & Service holder & 7 & 13.30 \\
history & Poor classLower middle class & 28 & 4.4017 .80 \\
& Middle class & 28 & 62.20 \\
Obstetric history & Higher class & 7 & 15.60 \\
Family history of breast disease & Regular & 35 & 77.8 \\
& Irregular & 5 & 11.1 \\
& Oligomenorrhoea & 3 & 6.7 \\
& Menorrhagia & 2 & 4.4 \\
& Nullipara & 19 & 42.22 \\
& Multipara & 26 & 57.78 \\
& Present & 7 & 15.56 \\
& Absent & 38 & 84.45 \\
\hline
\end{tabular}


Maximum patients presented with cyclical mastalgia (57.78\%) and mastalgia with lumpiness (44.4\%) and bilateral breasts involvement $(60 \%)$ (Table II) in initial visit.

Hormonal assay of the patients showed $60 \%$ had high serum Prolactin, 20\% had high serum Estrogen and 4.4\% had low serum Progesterone (Table III).

Among 45 respondents, all the respondents (100\%) had USG of both breasts, 19 (42.20\%) did Mammogram and $5(11.10 \%)$ did FNAC to confirm the nature of suspected breast lesion (Figure 1). More than fifty one percent of respondents underwent non-pharmacological and 48.9\% underwent pharmacological managements. More improvements occurred by pharmacological management in VAS pain score after completion of 6 months follow up (Table IV). In pharmacological treatment received group $40.91 \%$ respondents treated with Danazole and 59.09\% treated with Bromocriptine.

After 6 months follow up, $72.73 \%$ had pain improvement in pharmacologically treated group and $34.78 \%$ had pain improvement in non-pharmacological group. Significant difference had been found between both groups. Here VAS 0-2 was considered as pain improvement and VAS 4 and above was considered as non-improvement of pain (Table V).

Table Il Clinical findings of the respondents in initial visit $(\mathrm{N}=45)$

\begin{tabular}{llcc}
\hline Clinical presentation & Details & Frequency & Percentage \\
\hline Presentation of patients on initial & Mastalgia only & 11 & 24.4 \\
visit & Mastalgia +Lumpiness & 20 & 44.4 \\
& Mastalgia +Nodularity & 9 & 20 \\
& Mastalgia+ Breast & 5 & 11.1 \\
Side of involvement of Breast & Lump & & 13.3 \\
& Right breast & 6 & 26.7 \\
Types of Mastalgia & Left breast & 12 & 60 \\
& Both breasts & 27 & 57.78 \\
\hline & Cyclical & 26 & 42.22 \\
\hline
\end{tabular}

Table III Hormonal assay of the study subjects $(\mathrm{N}=45)$

\begin{tabular}{lccc}
\hline \multicolumn{1}{c}{ Hormone } & Normal & High & Low \\
\hline Serum Prolactin & $18(40)$ & $27(60)$ & - \\
Serum Estrogen & $36(80)$ & $9(20)$ & - \\
Serum Progesterone & $38(84.4)$ & - & $2(4.4)$ \\
\hline
\end{tabular}

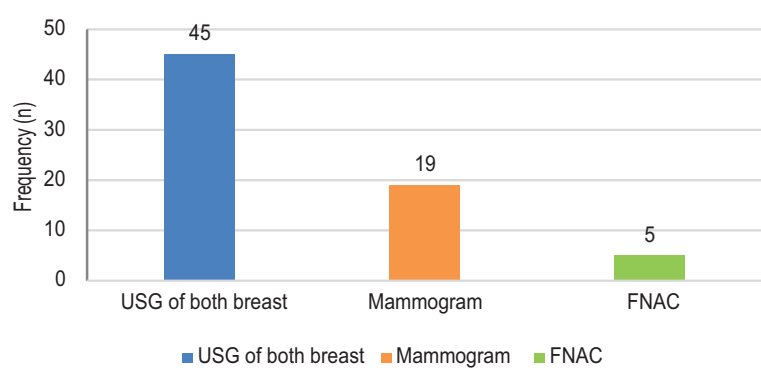

Figure 1 Types of investigations done $(\mathrm{N}=45)$

Table IV Distribution of VAS pain score at initial and subsequent visits in each group separately

\begin{tabular}{lcccccccc}
\hline $\begin{array}{l}\text { Pain Score } \\
\text { (VAS) }\end{array}$ & \multicolumn{3}{c}{$\begin{array}{c}\text { Non- pharmacological } \\
\text { Managements (n=23) }\end{array}$} \\
& Initialvisit & After1 M & After3 M & After6 M & Initialvisit & After1 M & After3 M & After6 M \\
\hline 0 & 0 & 0 & 3 & 5 & 0 & 5 & 9 & 11 \\
2 & 6 & 10 & 4 & 3 & 5 & 10 & 2 & 5 \\
4 & 12 & 10 & 8 & 9 & 11 & 4 & 9 & 4 \\
6 & 5 & 3 & 8 & 6 & 5 & 3 & 2 & 2 \\
8 & 0 & 0 & 0 & 0 & 1 & 0 & 0 & 0 \\
10 & 0 & 0 & 0 & 0 & 0 & 0 & 0 & 0 \\
\hline Total & 23 & & & 23 & 22 & & & 22 \\
\hline
\end{tabular}


Response of three domains of WHO-QOL in nonpharmacological and pharmacological treatment groups separately after completion of treatment after 6 months shows improvement was significantly higher in pharmacological group in all domains (Table V).

Side effects of different Pharmacological treatment options shows Danazole had maximum side effects, of them menstrual irregularity (15.6\%) was most common. Patients treated by Bromocriptine, maximum complained of headache (11.1\%). Patients treated nonpharmacologically by Evening Primrose oil (EPO) caused bloating in $6.7 \%$ and headache in $2.2 \%$ patients. (Table VI).

Table V Distribution of the respondents by 6 months follow up of non-pharmacological and pharmacological treatment using QOL parameters

\begin{tabular}{|c|c|c|c|c|c|c|}
\hline \multirow[b]{2}{*}{ Domains of QOL } & \multirow[b]{2}{*}{$\begin{array}{l}\text { Facets incorporated } \\
\text { within domains }\end{array}$} & \multicolumn{2}{|c|}{ Non pharmacological(n=23) } & \multicolumn{2}{|c|}{ Pharmacological(n=22) } & \multirow{2}{*}{$\begin{array}{c}\mathrm{P} \\
\text { value }\end{array}$} \\
\hline & & $\begin{array}{c}\text { Improved } \\
(\%) \\
\end{array}$ & $\begin{array}{c}\text { Not } \\
\text { Improved (\%) }\end{array}$ & $\begin{array}{c}\text { Improved } \\
(\%) \\
\end{array}$ & $\begin{array}{l}\text { Not } \\
\text { Improved }(\%)\end{array}$ & \\
\hline & Pain & $8(34.78)$ & $15(65.22)$ & $16(72.73)$ & $6(27.27)$ & $* 0.006$ \\
\hline & Physical health & $9(39.13)$ & $14(60.87)$ & $16(72.72)$ & $6(27.27)$ & $* 0.008$ \\
\hline \multirow[t]{3}{*}{ Physical domain } & Energy \& Fatigue & $8(34.78)$ & $15(65.22)$ & $15(68.18)$ & $7(31.82)$ & $* 0.001$ \\
\hline & Sleep \& Rest & $10(43.48)$ & $13(56.52)$ & $17(77.27)$ & $5(22.72)$ & $* 0.05$ \\
\hline & Self esteem & $7(30.43)$ & $16(69.57)$ & $14(63.64)$ & $8(36.36)$ & $* 0.031$ \\
\hline \multirow{4}{*}{$\begin{array}{l}\text { Psychological } \\
\text { domain }\end{array}$} & Concentration/ & $9(39.13)$ & $14(60.87)$ & $13(59.09)$ & $9(40.91)$ & *0.002 \\
\hline & Attention & & & & & \\
\hline & Negative feeling & $6(26.09)$ & $17(73.91)$ & $12(54.55)$ & $10(45.46)$ & $* 0.003$ \\
\hline & (Anxiety, Depression) & & & & & \\
\hline Social & Personal relationship & $8(34.78)$ & $15(65.21)$ & $12(54.55)$ & $10(45.46)$ & $* 0.151$ \\
\hline relationship & Sexual life & $7(30.43)$ & $16(69.57)$ & $13(59.09)$ & $9(40.91)$ & $* 0.08$ \\
\hline
\end{tabular}

*P value was determined by Chi-square test.

Table VI Distribution of side effects of different Pharmacological and non-pharmacological treatment options

\begin{tabular}{|c|c|c|c|c|c|}
\hline \multicolumn{2}{|l|}{ DANAZOLE } & \multicolumn{2}{|c|}{ BROMOCRIPTINEEV } & \multicolumn{2}{|c|}{ ENING PRIMROSE OIL(EPO) } \\
\hline Adverseeffect & Frequency (\%) & Adverse effect & Frequency $(\%)$ & Adverse effect & Frequency $(\%)$ \\
\hline Weight gain & $6(13.3)$ & Headache & $5(11.1)$ & Bloating & $3(6.7)$ \\
\hline Menstrual irregularity & $7(15.6)$ & Nausea & $2(4.4)$ & Headache & $1(2.2)$ \\
\hline Headache & $5(11.1)$ & Dyspepsia & $2(4.4)$ & & \\
\hline Nausea & $2(4.4)$ & Non specific & $3(6.7)$ & & \\
\hline Acne & $1(2.2)$ & & & & \\
\hline Non specific & $4(8.9)$ & & & & \\
\hline
\end{tabular}




\section{DISCUSSION}

Mastalgia with or without breast lump in FBD is common complaint among the patients and a cause of significant anxiety and fear of female breast cancer in Bangladesh as well as all over the world.

In this study maximum respondents were age between 31 to 35 years $(33.3 \%)$. The mean age of the respondents were $30.24 \pm 6.93$ years of SD. Similar observations were found in some previous studies by Scurr et al. ${ }^{9}$ and in a recent study done by Godazandeh et al. ${ }^{15}$

Observing the demographic data of our study respondents, maximum patients were married (64.4\%), housewife (62.20\%), multiparous $(57.78 \%)$, had regular menstrual cycle $(77.8 \%)$ and from middle class group $(62.20 \%)$. Most of our respondents did not have family history of breast disease $(84.45 \%)$. Similar observations were found in some previous study by Jahdi et al. ${ }^{2}$ and Çomçalý et al. ${ }^{16}$ showed majority of their respondents were housewife $^{2}$, unemployed ${ }^{16}$, married ${ }^{2,15,16}$ and multiparous $^{2,15,16}$.

Clinical presentations in initial visit showed maximum respondent had cyclical mastalgia (57.78\%) and $42.22 \%$ had non-cyclical mastalgia. Similar observation was noted in a previous study by Rajswaroob et al. ${ }^{17}$ and Nirhale et al. ${ }^{8}$

In this study maximum respondents $(60 \%)$ had both breasts involvement, 26.7\% had left breast and 13.3\% had right breast involvement. In a previous study by Sangma MB et al. ${ }^{18}$ observed maximum respondents had right breast involvement (48\%), the left breast was affected in $40 \%$ patients while only $12 \%$ cases both breasts were affected, that differs from our observation. In this study maximum respondents presented with mastalgia with lumpiness (44.4\%), followed by mastalgia only $(24.4 \%)$, mastalgia with nodularity (20\%) and only $11.1 \%$ had mastalgia with breast lump. In a previous study of 49 patients by Nirhale et al. ${ }^{8}$, it was observed that 'mastalgia only' was the most common symptom and accounted for $61.25 \%$ patients, beside $35 \%$ had 'mastalgia with lump', which is different from our observation. In our study hormonal levels of respondents showed, 60\% had high serum Prolactin, 20\% had high serum Estrogen and 4.4\% had low serum Progesterone level. Smith et al. ${ }^{19}$ showed in his previous study, the frequently detected hormonal abnormality related with mastalgia was increased Prolactin level, Progesterone deficiency and Estrogen excess.
USG of both breasts was done for all 45 patients $(n=45)$, Mammogram was done for 19 (42.2\%) patients and FNAC was done for $5(11.10 \%)$ patient, who presented with breast lump along with mastalgia to confirm fibroadenosis/ fibroadenoma and to rule out malignancy and suspected breast lesions. In a previous study by Rajswaroob et al. ${ }^{17}$ did same type of investigations.

In this study $51.1 \%$ respondents underwent nonpharmacological treatment by LSM and EPO and 48.9\% underwent pharmacological treatment, where $40.91 \%$ respondents treated with Danazole and 59.09\% treated with Bromocriptine depending on the selection criteria.

In this study quality of life (QOL) in non-pharmacological treatment receiving group- in physical domain: pain $34.78 \%$, physical health $39.13 \%$, energy and fatigue $34.78 \%$ and sleep and rest $43.48 \%$ had improvement. In psychological domain: $30.43 \%$ had improvement of selfesteem, $39.13 \%$ had improvement in concentration/ attention and $26.09 \%$ had improvement in negative feeling. In social relationship domain: in personal relationship $34.78 \%$ and in sexual life $30.63 \%$ had improvement. Beside in pharmacological treatment receiving group in physical domain: pain $72.73 \%$, physical health $72.72 \%$, energy and fatigue $68.18 \%$ and sleep and rest $77.27 \%$ had improvement. In psychological domain: in self-esteem $63.64 \%$, concentration/attention $59.09 \%$ and $54.55 \%$ negative feeling had improvement. In social domain: $54.55 \%$ personal relationship and 59.09\% sexual life had improvement. In all domains improvements were significantly higher in pharmacological group.

Similar observation was seen in a previous study by Rajswaroob et al. ${ }^{17}$ where he showed drug treatment was significantly effective for mastalgia. P. Ganz et al. observed mood and emotional functioning were same among all patients, with no differences by type of medical treatment received ${ }^{20}$ which is abit differ from our observation.

In this study majority of side effects occurred due to Danazole. Chronologically they are menstrual irregularity (15.6\%), weight gain $(13.3 \%)$, headache $(11.1 \%)$, nausea (4.4\%), acne (2.2\%) and nonspecific side effects (8.9\%). Beside headache (11.1\%), nausea (4.4\%), dyspepsia (4.4\%) and nonspecific side effects $(6.7 \%)$ due to Bromocriptine. Whereas only $6.7 \%$ had bloating and $2.2 \%$ had headache due to Evening Primrose oil (EPO). 
Here a single patient sometimes complained of multiple side effects.

Almost similar observation was seen in some previous study by Rajswaroob et al. ${ }^{17}$ and Neogi $\mathrm{P}$ et al. ${ }^{21}$ and Nirhale et al. ${ }^{8}$

There are some limitations of our study. This study was performed in a single tertiary care hospital among small available population size.

\section{Conclusion}

Mastalgia, being a common symptom of fibrocystic breast disease, causes anxiety among the women of reproductive age group and burdens the health care facilities of our country. In this study, we found pharmacological managements by Danazole or Bromocriptine in precisely selected group of patients were well tolerated and a dramatic improvement was observed in overall quality of life of our patients. Despite of having various side effects of different pharmacological managements of mastalgia, we recommend timely use of them in the precisely selected patients of fibrocystic breast disease can help in reduction of their sufferings, cost of prolonged treatments by improving the quality of life in a relatively shorter period of time.

Further large study is recommended involving multiple centers and long term follow up.

Authors' contribution: Mostary S, Maitra TK were involved in study designing, data collection, compiling, data analysis. Mostary S. wrote the manuscript. Rests were involved in overall supervision.

Conflict of interest: Nothing to declare.

\section{REFERNCES}

1. Ameen F, Reda SA, El-Shatoury SA, Riad EM, Enany ME, Alarfaj AA. Prevalence of antibiotic resistant mastitis pathogens in dairy cows in Egypt and potential biological control agents produced from plant endophytic actinobacteria. Saudi J Biol Sci 2019 Nov 1;26(7): 1492-8.

2. Jahdi F, Tolouei R, Samani LN, Hashemian M, Haghani H, Mojab F, et al. Effect of evening primrose oil and vitamin b6 on pain control of cyclic mastalgia associated with fibrocystic breast changes: a triple-blind randomized controlled trial. Shiraz E-Medical Journal 2019 May 31;20(5):e81243.
3. Kanat BH, Atmaca M, Girgin M, Ilhan YS, Bozdað A, Özkan Z, et al. Effects of mastalgia in young women on quality of life, depression, and anxiety levels. Indian $\mathrm{J}$ Surg 2016 Apr;78(2):96-9.

4. Marchant DJ. Inflammation of the breast. Obstetrics and Gynecology Clinics 2002 Mar 1;29(1):89-102.

5. Salati SA, Alhumaid AA. Mastalgia: A narrative literature review of current understanding and management. East Central Afr J Surg 2018 Jul 16;23(1):42-51.

6. Cornell LF, Sandhu NP, Pruthi S, Mussallem DM. Current Management and Treatment Options for Breast Pain. In Mayo Clinic Proceedings 2020; 95(3):574-80

7. Nicola LP.B, Shazia P.H., Kirwan C. Clinical management of idiopathic mastalgia: a systemic review. J Prime Health Care 2018; 10(4): 312-23.

8. Nirhale DS, Dhende M, Shingade P, Chavan S, Sonawane T, Kulkarni G. A study on clinical profile and management of mastalgia. International Surgery Journal 2018 Apr 21;5(5):1889-93.

9. Scurr J, Hedger W, Morris P, Brown N. The prevalence, severity, and impact of breast pain in the general population. The Breast Journal 2014 Sep; 20(5):508-13.

10. Murshid, KR. A review of mastalgia in patients with fibrocystic breast changes and the non-surgical treatment options', Journal of Taibah University Medical Sciences $2011 ; 6(1): 1-18$

11. Pruthi, S, Wahner-Roedler, DL, Torkelson, CJ, Cha, SS, Thicke, LS, Hazelton, JH et al. Vitamin E and evening primrose oil for management of cyclical mastalgia: A randomized pilot study. Alternative Medicine Review 2010;15(1):59-67.

12. Ortiz-Mendoza CM, Lucas Flores MA, Domville Ede G. Mastalgia treatment with tamoxifen'. [Article in Spanish]. Ginecol Obstet Mex 2003;71:502-7.

13. Jain BK, Bansal A, Choudhary D, Garg PK, Mohanty D. Centchroman vs tamoxifen for regression of mastalgia: a randomized controlled trial. International Journal of Surgery 2015 Mar 1; 15:11-6.

14. Groen JW, Grosfeld S, Bramer WM, Ernst MF, Mullender MM. Cyclic and non-cyclic breast-pain: A systematic review on pain reduction, side effects, and quality of life for various treatments. European Journal of Obstetrics \& Gynecology and Reproductive Biology 2017 Dec 1; 219:74-93.

15. Godazandeh G, Ala S, Motlaq TM, Sahebnasagh A, Bazi A. The comparison of the effect of flaxseed oil and vitamin E on mastalgia and nodularity of breast fibrocystic: a randomized double-blind clinical trial. Journal of Pharmaceutical Health Care and Sciences 2021 Dec;7(1): $1-8$. 
16. Çomçalý B, Kocaoz S, Özdemir BA, Parlak Ö, Korukluoðlu B. Effects of sagging breasts and other risk factors associated with mastalgia: a case-control study. Scientific Reports 2021 Jan 29;11(1):1-7.

17. Rajswaroob U, Kannan R, Kannan NS, Tirouaroul T. Effectiveness of centchroman on regression of fibroadenosis and mastalgia. Journal of clinical and diagnostic research: JCDR 2016 Oct;10(10):PC10-14.

18. Sangma MB, Panda K, Dasiah S. A clinico-pathological study on benign breast diseases. Journal of clinical and diagnostic research: JCDR 2013 Mar;7(3):503-6.
19. Smith RL, Pruthi S, Fitzpatrick LA. Evaluation and management of breast pain. In Mayo Clinic Proceedings 2004 Mar 1;79(3):353-72.

20. Ganz PA, Kwan L, Stanton AL, Krupnick JL, Rowland JH, Meyerowitz BE, et al. Quality of Life at the End of Primary Treatment of Breast Cancer/ : First Results From the Moving Beyond Cancer Randomized Trial. Journal of the National Cancer Institute March 2004; 96(5): 376-87.

21. Neogi P, Manwatkar S, Singh SK, Kola A, Imran Q, Katyayan I, et al. A comparative study of Centchroman, Tamoxifen and Danazol in management ofcyclical mastalgia. International Surgery Journal. 2019 Jan $28 ; 6(2): 365-8$ 